\title{
Peroxo Salts as Initiators of Vinyl Polymerization IV. Polymerization of Acrylonitrile by the Peroxo- monosulphate-Oxovanadium(IV) System ${ }^{\dagger}$
}

\author{
G. Manivannan and P. Maruthamuthu* \\ Department of Energy, University of Madras, A. C. College Campus, \\ Madras 600 025, India
}

(Received June 1, 1988)

\begin{abstract}
A detailed kinetic study of the aqueous polymerization of acrylonitrile (AN) initiated by peroxomonosulphate $\left(\mathrm{HSO}_{5}{ }^{-}, \mathrm{PMS}\right)$-oxovanadium(IV) redox system has been made in the temperature range $30^{\circ}-60^{\circ} \mathrm{C}$ under dearated conditions at a constant ionic strength $(\mu=$ 1.20). The effects of [monomer], [PMS], [oxovanadium(IV)], $\left[\mathrm{H}^{+}\right], \mu$ and temperature on rate of polymerization, $R_{\mathrm{p}}$ were investigated and the $R_{\mathrm{p}}$ was found to be proportional to [AN] ${ }^{1.5}$ $\left[\mathrm{HSO}_{5}{ }^{-}\right]^{0.5}$ [oxovanadium(IV)] ${ }^{0.5}$. The kinetic and thermodynamic parameters were evaluated and are discussed. A suitable reaction scheme involving redox reaction of $\mathrm{HSO}_{5}{ }^{-}$and oxovanadium(IV) with mutual termination is proposed. The expression for degree of polymerization, $\bar{X}_{n}$ was obtained by molecular weight determination of the formed polymers. A comparison was also made with a similar redox system involving peroxodiphosphate.

KEY WORDS Thermal Polymerization / PeroxomonosulphateOxovanadium(IV) Redox System / Rate of Polymerization / Monomer / Peroxomonosulphate / Oxovanadium(IV) / Temperature Effect / Degree of Polymerization /
\end{abstract}

Our previous studies ${ }^{1-3}$ demonstrated clearly that, peroxomonosulphate $\left(\mathrm{HSO}_{5}{ }^{-}, \mathrm{PMS}\right)$ can be employed as an efficient water soluble initiator for vinyl polymerization in coupling with suitable reducing agents involving redox reactions. As an extention of this investigation, we now report peroxomonosulphateoxovanadium(IV) for aqueous, thermal polymerization of acrylonitrile. In the present study, the oxovanadium(IV) ion is represented as $\mathrm{VO}^{2+}$ in all discussions.

The kinetics of reduction of PMS by oxovanadium(IV) ion in acidic solution ${ }^{4}$ and the use of trapping agents like $\mathrm{HN}_{3}$ and $\mathrm{Ce}$ (III) proved that the reaction of PMS with oxovanadium(IV) involved a free radical mechanism. Moreover, formation of $\mathrm{SO}_{4}{ }^{-}$radical as the transient intermediate was invoked in one electron reduction of $\mathrm{PMS}^{5,6}$ and in pulse radiolytic studies ${ }^{7}$ of the reduction of PMS by hydrated electrons.

The metal ion, $\mathrm{VO}^{2+}$ undergoes oxidation to produce $\mathrm{VO}_{2}{ }^{+}$which can be ineffective as initiating species $^{8}$ but the reaction proceeds with radical intermediates. Furthermore, in redox systems involving metal ion as one of the components (as either reducing or oxidizing agent), linear termination is also a possible reaction and both oxidative and reductive terminations of the polymer radicals by metal ions have already been encountered. ${ }^{9-13}$

The essential difference between the PMS$\mathrm{VO}^{2+}$ system and our previously reported ${ }^{3}$ PMS- $\mathrm{Co}^{2+}$ system is that the product formed,

† This paper constitutes a portion of the paper accepted for presentation in "IUPAC 32nd International Symposium on Macromolecules (MACRO 88)" held at Kyoto, Japan, 1-6 August 1988. 
$\mathrm{Co}$ (III) in the latter system is capable of initiating polymerization, whereas in the present investigation, $\mathrm{VO}_{2}{ }^{+}$formed is a stable species and not capable of initiating polymerization. However, the formation of $\mathrm{SO}_{4}{ }^{-}$as the reactive intermediate has added interest and led to choosing this metal ion, $\mathrm{VO}^{2+}$ as reducing agent component of redox initiator with peroxomonosulphate.

\section{EXPERIMENTAL}

\section{Materials}

Solutions of $\mathrm{HSO}_{5}{ }^{-}$were prepared as reported in a previous work. ${ }^{3}$ Fresh solutions of

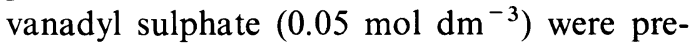
pared for all experiments and standardized by permanganometry in acid medium to pale pink colour. ${ }^{14}$ Doubly distilled water was always used for the experiments.

\section{Methods}

The purification of the monomer and experimental methods are essentially as described earlier. ${ }^{2,3}$ All the experiments were conducted in aqueous solution at $0.10 \mathrm{~mol} \mathrm{dm}^{-3}$ $\left[\mathrm{H}^{+}\right]$under deaerated conditions (with purified $\mathrm{N}_{2}$ ) at $40^{\circ} \mathrm{C}$ with the reactants in the following concentration range

$$
\begin{aligned}
{[\mathrm{AN}] } & =6.08-9.88 \times 10^{-1} \mathrm{~mol} \mathrm{dm}^{-3} \\
{[\mathrm{PMS}] } & =0.40-3.97 \times 10^{-3} \mathrm{~mol} \mathrm{dm}^{-3} \\
{\left[\mathrm{VO}^{2+}\right] } & =1.07-5.99 \times 10^{-4} \mathrm{~mol} \mathrm{dm}^{-3} \\
\mu & =1.20
\end{aligned}
$$

The molecular weights $\left(\bar{M}_{w}\right)$ of the formed polymers were obtained by viscometry by extrapolation methods of Huggins ${ }^{15}$ and Kraemer $^{16}$ and the Mark-Houwink equation, ${ }^{17}[\eta]=3.35 \times 10^{-4}\left(\bar{M}_{w}\right)^{0.72}$ was used for poly(acrylonitrile) in dimethyl formamide at $30^{\circ} \mathrm{C}$.

\section{RESULTS AND. DISCUSSION}

The polymerization was found to start without any significant induction period. The radical nature of the reaction was evident by the inhibition of polymerization in presence of atmospheric oxygen. The polymerization proceeded approximately for twenty minutes and then attained steady state (Figure 1).

\section{Effect of [monomer] on $R_{\mathrm{p}}$}

The polymerization reactions were carried out with varying concentrations of acrylonitrile $\left([\mathrm{AN}]=6.08-9.88 \times 10^{-1} \mathrm{~mol} \mathrm{dm}^{-3}\right)$ at constant [PMS] and $\left[\mathrm{VO}^{2+}\right](0.97-4.94 \times$ $10^{-3} \mathrm{moldm}^{-3}$ and $4.92 \times 10^{-4} \mathrm{~mol} \mathrm{dm}^{-3}$ respectively) at $40^{\circ} \mathrm{C}$ with $0.10 \mathrm{~mol} \mathrm{dm}^{-3}\left[\mathrm{H}^{+}\right]$ and constant ionic strength $\left(1.20 \mathrm{~mol} \mathrm{dm}^{-3}\right)$ to observe the effects of variation of monomer concentration on $R_{\mathrm{p}} . R_{\mathrm{p}}$ was found to vary linearly with increase in [monomer] and the plot of $R_{\mathrm{p}}$ versus $[\mathrm{AN}]^{1.5}$ (Figure 2) with lines passing through the origin indicated the 1.5 order dependence of $R_{\mathrm{p}}$ on [monomer]. Similarly, plots of $\log R_{\mathrm{p}}$ versus $\log$ [AN] were also found to be linear with a slope equal to 1.5. The higher monomer order normally represents the monomer involvement in the primary radical producing reactions.

\section{Effect of $[P M S]$ on $R_{\mathrm{p}}$}

The variation of [PMS] in the range $0.40-$ $3.97 \times 10^{-3} \mathrm{~mol} \mathrm{dm}^{-3}$ at fixed [monomer] and $\left[\mathrm{VO}^{2+}\right]\left(0.99 \mathrm{~mol} \mathrm{dm}^{-3}\right.$ and $4.92 \times 10^{-4} \mathrm{~mol}$ $\mathrm{dm}^{-3}$ respectively) with an ionic strength of 1.20 in presence of $\mathrm{H}^{+}\left(0.10 \mathrm{~mol} \mathrm{dm}^{-3}\right)$ was carried out to investigate the effect of [PMS] on $R_{\mathrm{p}}, R_{\mathrm{p}}$ was found to increase linearly upto $1.06 \times 10^{-3} \mathrm{~mol} \mathrm{dm}^{-3}$ at various $\left[\mathrm{VO}^{2+}\right.$ ] $\left(1.07-4.92 \times 10^{-4} \mathrm{~mol} \mathrm{dm}^{-3}\right) . R_{\mathrm{p}}$ was found to be proportional to [PMS] $]^{0.5}$, which was revealed by a linear plot of $R_{\mathrm{p}}$ versus $[\mathrm{PMS}]^{0.5}$ (Figure 3) passing through the origin.

\section{Effect of $\left[\mathrm{VO}^{2+}\right]$ on $\mathrm{R}_{\mathrm{p}}$}

The concentration of $\mathrm{VO}^{2+}$ was varied in the range $1.07-5.99 \times 10^{-4} \mathrm{~mol} \mathrm{dm}^{-3}$ at constant [monomer], $\left[\mathrm{H}^{+}\right]$and ionic strength $\left(0.99 \mathrm{~mol} \mathrm{dm}^{-3}, 0.10 \mathrm{~mol} \mathrm{dm}^{-3}\right.$ and $1.20 \mathrm{~mol}$ $\mathrm{dm}^{-3}$ respectively) with varying [PMS] (1.18$4.92 \times 10^{-3} \mathrm{~mol} \mathrm{dm}^{-3}$ ). $R_{\mathrm{p}}$ was found to in- 


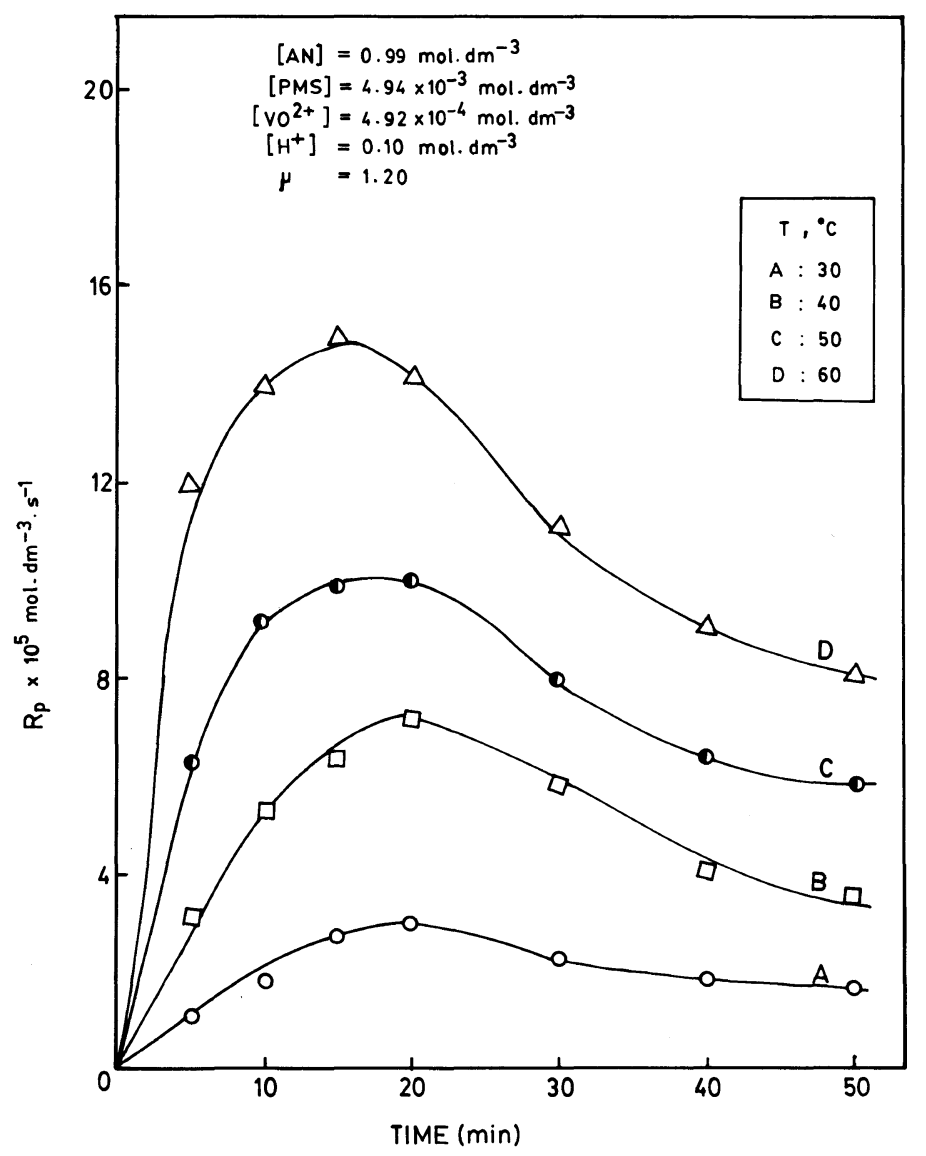

Figure 1. Effect of time on rate of polymerization, $R_{\mathrm{p}}$.

crease with increase in $\left[\mathrm{VO}^{2+}\right]$ with 0.5 order dependence. A plot of $R_{\mathrm{p}}$ versus $\left[\mathrm{VO}^{2+}\right]^{0.5}$ was also linear with zero intercept (Figure 4) showing the half-order dependence of $R_{\mathrm{p}}$ on $\left[\mathrm{VO}^{2+}\right]$.

Effect of Ionic Strength $(\mu)$ and $\left[H^{+}\right]$on $R_{\mathrm{p}}$

Ionic strength $(\mu)$ was varied in the range $0.80-1.50$ keeping all other reactants constant at $40^{\circ} \mathrm{C}\left([\mathrm{AN}]=0.99 \mathrm{~mol} \mathrm{dm}^{-3}[\mathrm{PMS}]=\right.$ $4.94 \times 10^{-3} \mathrm{~mol} \mathrm{dm}^{-3}, \quad\left[\mathrm{VO}^{2+}\right]=4.92 \times 10^{-4}$ moldm ${ }^{-3}$ and $\left.\left[\mathrm{H}^{+}\right]=0.10 \mathrm{~mol} \mathrm{dm}^{-3}\right) . \quad R_{\mathrm{p}}$ showed a slow increase upto $\mu=1.20$ as was normally observed for the reaction between oppositely charged ions. ${ }^{18}$ Similarly, $\left[\mathrm{H}^{+}\right]$ was varied from $0.06-0.50 \mathrm{~mol} \mathrm{dm}^{-3}$ at constant ionic strength (1.20) and at constant concentrations of $\mathrm{AN}, \mathrm{PMS}, \mathrm{VO}^{2+} . R_{\mathrm{p}}$ was found to increase a little and then decrease upto $0.50 \mathrm{~mol} \mathrm{dm}^{-3}\left[\mathrm{H}^{+}\right]$.

\section{Effect of Temperature on $R_{\mathrm{p}}$}

The temperature variation of the reaction exerted a significant positive influence on $R_{\mathrm{p}}$ which increased with temperature. From the plot of $\log R_{\mathrm{p}}$ versus $T^{-1}$ (Figure 5), the overall activation energy, $E_{\mathrm{a}}$ was evaluated to be $56.10 \mathrm{~kJ} \mathrm{~mol}^{-1}$.

\section{Degree of Polymerization, $\bar{X}_{n}$}

The variation of [monomer], [PMS] and $\left[\mathrm{VO}^{2+}\right]$ showed a marked influence on the 


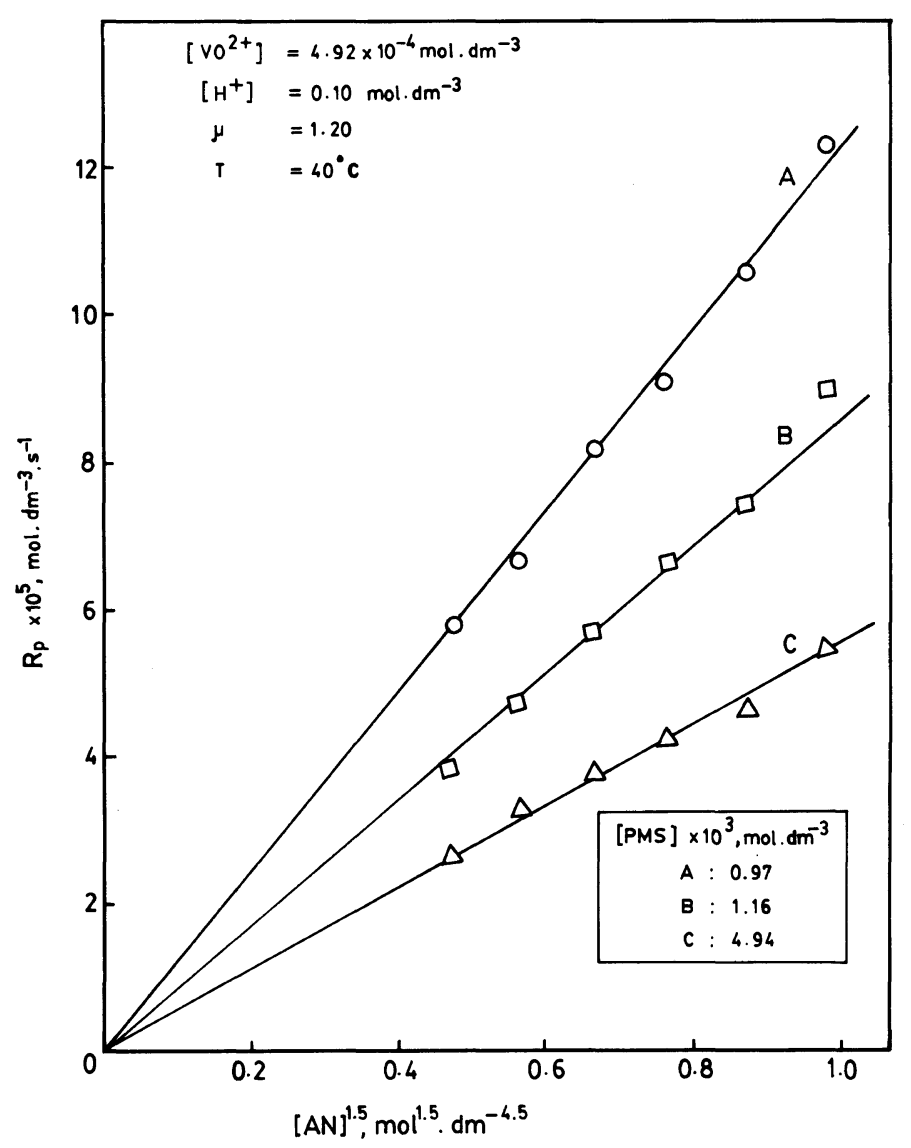

Figure 2. Effect of [monomer] on $R_{\mathrm{p}}$ at constant [PMS] and $\left[\mathrm{VO}^{2+}\right]$.

degree of polymerization, $\bar{X}_{n}$. Increase of [monomer], [PMS] and $\left[\mathrm{VO}^{2+}\right]$ showed a marked influence on the degree of polymerization, $\bar{X}_{n}$. With increase in monomer, $\bar{X}_{n}$ increased, whereas the increase in [PMS] and $\left[\mathrm{VO}^{2+}\right]$ had a negative influence on $\bar{X}_{n}$. The individual plot of $\log \bar{X}_{n}$ versus $\log$ [monomer], and $\log [\mathrm{PMS}]$ and $\log \left[\mathrm{VO}^{2+}\right]$ revealed the above effect (Figure 6).

\section{REACTION SCHEME AND MECHANISM}

$R_{\mathrm{p}}$ was found to depend upon [monomer] ${ }^{1.5}$ $[\mathrm{PMS}]^{0.5}$ and $\left[\mathrm{VO}^{2+}\right]^{0.5}$. In acidic solution, the existence of oxovanadium(IV) as $\mathrm{VO}^{2+}$ was confirmed by an electronic spectral and paramagnetic resonance data. ${ }^{19,20}$ The data obtained at high acidities also indicated the presence of $\mathrm{VO}^{2+}$ ions (but did not rule out $\left.\mathrm{V}(\mathrm{OH})_{2}{ }^{2+}\right)$. At higher $\mathrm{pH}$, the measurements were difficult to interpret because of the presence of hydrolysis products of both the oxidation states V(IV) and V(V). Indeed, the complexities which arise at $\mathrm{pH} 2.5$ due to the formation of isopolyvanadates and vanadylvanadates, have been recently investigated. ${ }^{21}$ The standard potential ${ }^{22}$ for the system $\mathrm{V}^{5+} / \mathrm{V}^{4+}$ was $0.97 \mathrm{~V}$ in $\mathrm{H}_{2} \mathrm{SO}_{4}$. The $E^{0}$ value for the reaction,

$$
\mathrm{VO}^{2+}+3 \mathrm{H}_{2} \mathrm{O}=\mathrm{V}(\mathrm{OH})_{4}^{+}+2 \mathrm{H}^{+}+\mathrm{e}^{-}
$$

is reported ${ }^{23}$ as $-1.00 \mathrm{~V}$. Since in the present polymerization study, the $\mathrm{pH}$ of the reaction medium is $1.25-1.30$, the active species of 


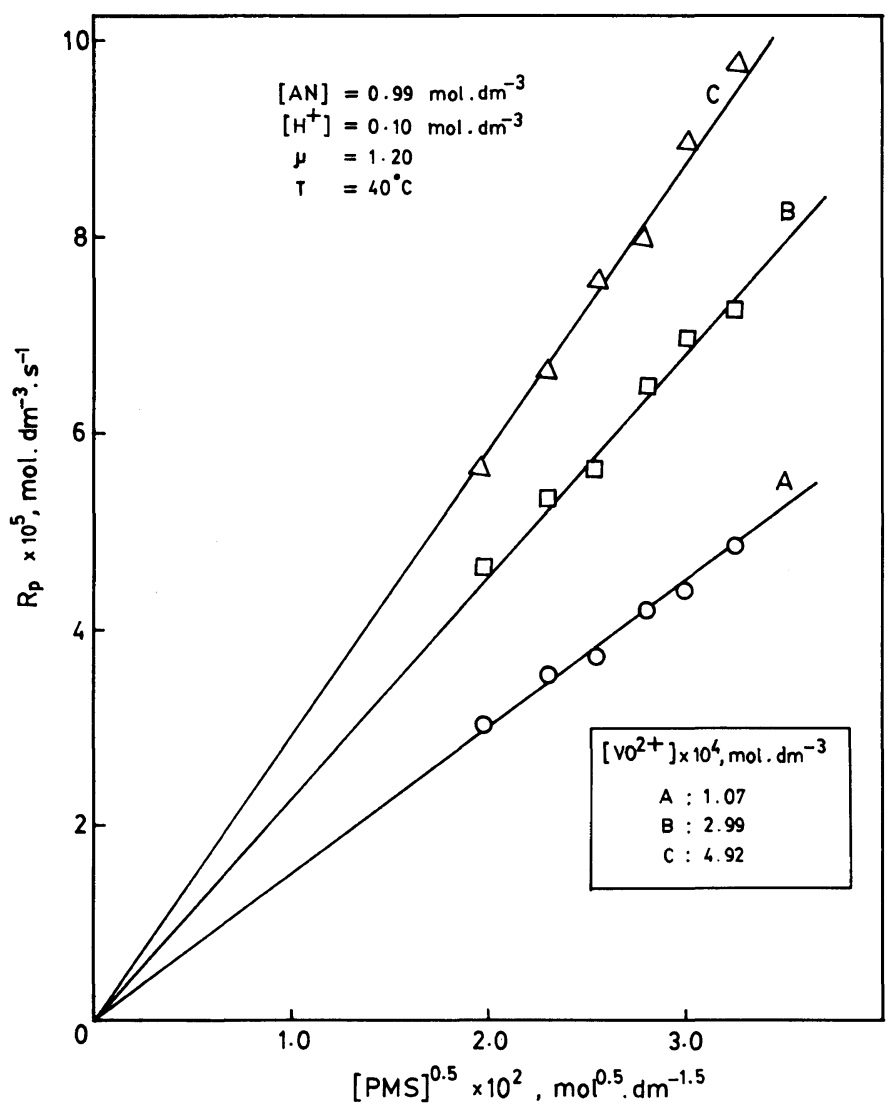

Figure 3. Effect of $[\mathrm{PMS}]$ on $R_{\mathrm{p}}$ at constant [monomer] and $\left[\mathrm{VO}^{2+}\right]$.

oxovanadium(IV) is V(IV). The V(IV) undergoes oxidation by peroxomonosulphate to give the final product $\mathrm{V}(\mathrm{V})$ via free radical intermediates.

There is no reference in the literature with $\mathrm{V}(\mathrm{V})$ as a single initiator for polymerization. Littler and Waters ${ }^{24}$ indicated that $\mathrm{V}(\mathrm{V})$ does not initiate vinyl polymerization in the absence of reducing agents in acidic solution. In the oxidation of vanadyl ion by peroxodisulphate in aqueous acid solution reported by Anderson et al. ${ }^{25}$ interactions of anions with $\mathrm{VO}^{2+}$ were observed and the authors related this interaction to the fact that anions acted as ligands in complexes of $\mathrm{VO}^{2+}$. The extinction coefficient at $770 \mathrm{~nm}$ for $\mathrm{VO}^{2+}$ was observed to be constant at pH 1.0-3.5, emphasising the presence of the only species $\mathrm{VO}^{2+}$ in this $\mathrm{pH}$ range. Since the present investigation was carried out in the $\mathrm{pH}$ range $1.25-1.30$, it is reasonable to assume that only the $\mathrm{VO}^{2+}$ ion is present as the rate of polymerization was observed in the hydrolysis.

A mild inverse hydrogen ion dependence on the rate of polymerization was observed in the present investigation as reported earlier. ${ }^{4}$ This may be due to a rapid pre-equilibrium step with the formation of a precursor complex, VOSO $_{5}$.

$$
\mathrm{HSO}_{5}{ }^{-}+\mathrm{VO}^{2+} \stackrel{K_{1}}{\rightleftharpoons} \mathrm{VO} \cdot \mathrm{OOSO}_{3}+\mathrm{H}^{+}
$$

This precursor complex undergoes reaction with monomer to produce a monomer radical. 


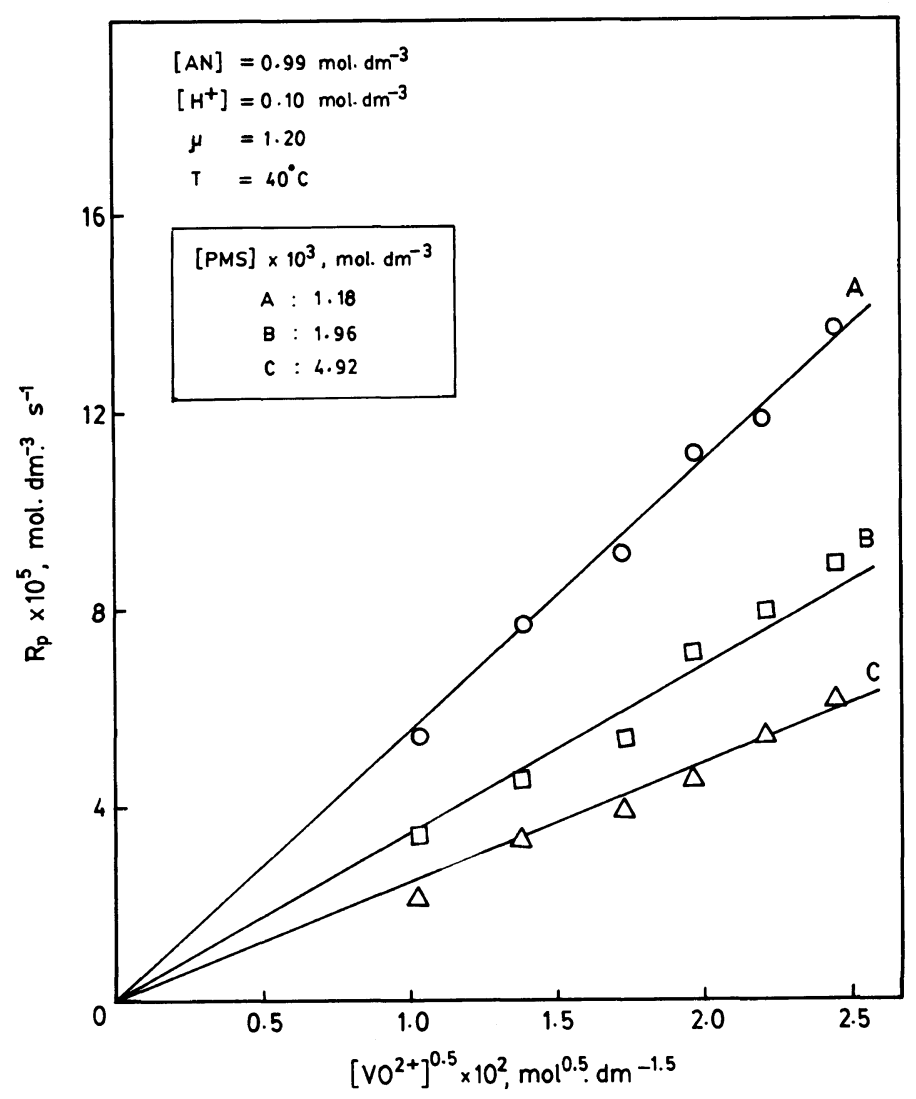

Figure 4. Effect of $\left[\mathrm{VO}^{2+}\right]$ on $R_{\mathrm{p}}$ at constant [monomer] and [PMS].

Since the deliberately added $\mathrm{H}^{+}$reverted the equilibrium to the left hand side resulting in the decrease of the complex concentration, the rate of polymerization decreased with $\left[\mathrm{H}^{+}\right]$.

Based on the above findings, following reaction scheme is proposed, involving the complex formation between PMS and $\mathrm{VO}^{2+}$ followed by initiation of the formed complex with monomer.

\section{Initiation}

$$
\begin{gathered}
\mathrm{HSO}_{5}{ }^{-}+\mathrm{VO}^{2+} \stackrel{K_{1}}{\rightleftharpoons} \operatorname{VOSO}_{5}\left(\mathrm{C}_{1}\right)+\mathrm{H}^{+} \\
\mathrm{C}_{1}+\mathrm{M} \stackrel{k_{1}}{\longrightarrow} \mathrm{M}_{1}{ }^{\cdot}+\mathrm{VO}_{2}{ }^{+} \\
\left(\mathrm{M}^{\cdot}-\mathrm{SO}_{4}{ }^{-}\right)
\end{gathered}
$$

\section{Propagation}

$$
\begin{aligned}
& \mathrm{M}+\mathrm{M}_{1} \cdot \stackrel{k_{\mathrm{p}}}{\longrightarrow} \mathrm{M}_{2} . \\
& \mathrm{M}+\mathrm{M}_{2} \stackrel{k_{\mathrm{p}}}{\longrightarrow} \mathrm{M}_{3} . \\
& \mathrm{M}+\mathrm{M}_{n-1} \stackrel{k_{\mathrm{p}}}{\longrightarrow} \mathrm{M}_{n} .
\end{aligned}
$$

\section{Termination}

$$
\mathrm{M}_{n} \cdot \mathrm{M}_{n} \stackrel{k_{\mathrm{t}}}{\longrightarrow} \text { Polymer }
$$

The possibility of the formation of hydroxyl radical $(\dot{O} H)$ can be ruled out on the basis that, the formed complex reacts with monomer to give $\mathrm{M}^{\cdot}$ with sulphate group $\left(\mathrm{M}-\mathrm{SO}_{4}{ }^{-}\right)$and $\mathrm{VO}^{2+}$.

Applying the steady state approximation for 


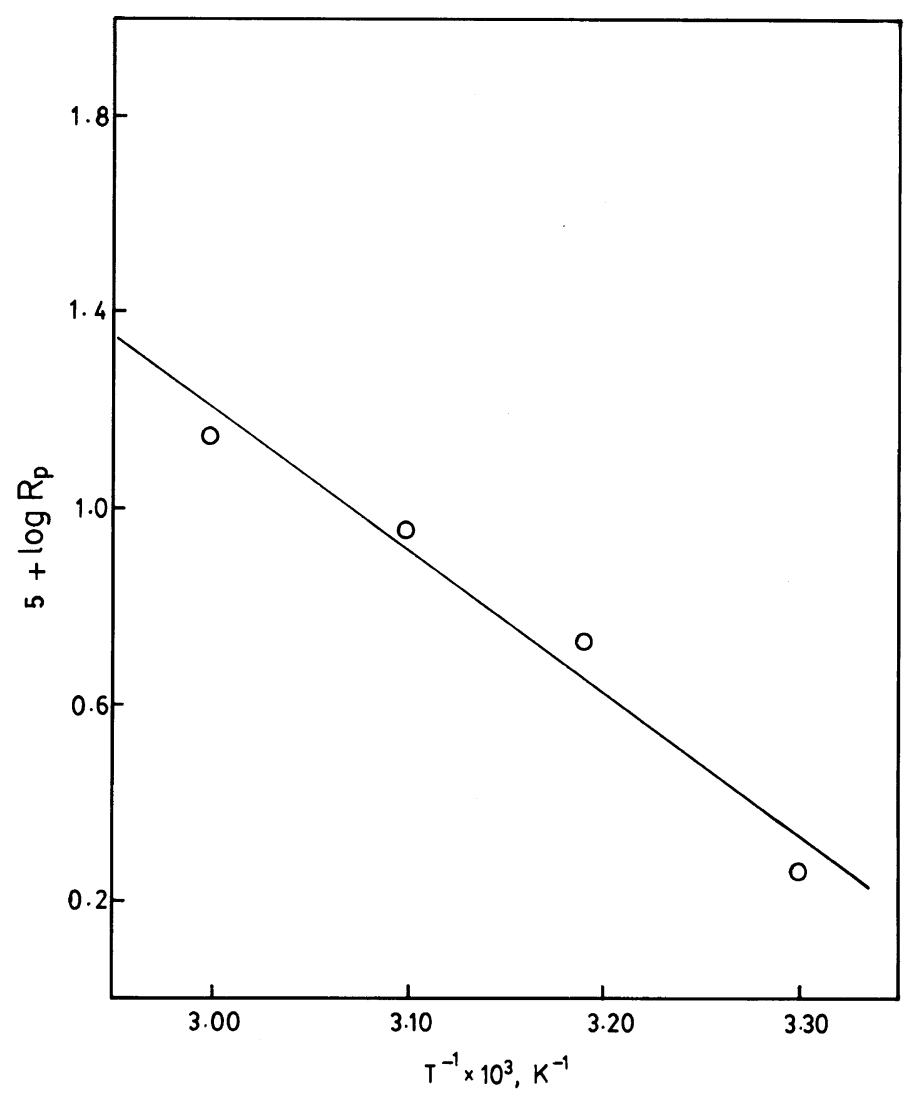

Figure 5. Effect of temperature on $R_{\mathrm{p}}$.

both the primary and chain free radicals, and assuming only the mutual termination as the effective one, the observed expressions for $R_{\mathrm{p}}$ and the degree of polymerization are given below.

$$
\begin{aligned}
R_{\mathrm{p}}= & k_{\mathrm{p}}\left[\frac{k_{1} \cdot K_{1}}{2 k_{\mathrm{t}}}\right]^{0.5} \\
& \times \frac{[\mathrm{M}]^{1.5}\left[\mathrm{HSO}_{5}{ }^{-}\right]^{0.5}\left[\mathrm{VO}^{2+}\right]^{0.5}}{\left[\mathrm{H}^{+}\right]^{0.5}}
\end{aligned}
$$

Since the concentration of $\mathrm{H}^{+}$is very low compared to the concentrations of other reactants, its effect can be neglected in the absence of any $\mathrm{H}^{+}$added deliberately and by substituting the constant $k_{\mathrm{i}}$ for $\left(k_{1} \cdot K_{1} / 2\right)$,

$R_{\mathrm{p}}=k_{\mathrm{p}} \cdot\left(\frac{k_{\mathrm{i}}}{k_{\mathrm{t}}}\right)^{0.5}[\mathrm{M}]^{1.5}\left[\mathrm{HSO}_{5}{ }^{-}\right]^{0.5}\left[\mathrm{VO}^{2+}\right]^{0.5}$

$$
\bar{X}_{n}=k_{\mathrm{p}}\left\{\frac{[\mathrm{M}]}{k_{\mathrm{t}} \cdot k_{\mathrm{i}}\left[\mathrm{HSO}_{5}{ }^{-}\right]\left[\mathrm{VO}^{2+}\right]}\right\}^{0.5}
$$

This expression for the degree of polymerization reveals the dependence of $\bar{X}_{n}$ on

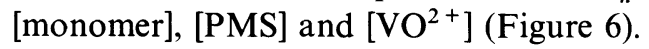

\section{Thermodynamic Parameters}

The energy of activation $\left(E_{\mathrm{a}}\right)$ obtained from the plot of $\log R_{\mathrm{p}}$ versus $T^{-1}$ and the thermodynamic parameters, $\Delta G^{\neq}, \Delta H^{\ddagger}$, and $\Delta S^{\neq}$ computed using standard equations are,

$$
\begin{aligned}
\Delta G^{\neq} & =88.49 \mathrm{~kJ} \mathrm{~mol}^{-1} \\
\Delta H^{\ddagger} & =53.49 \mathrm{~kJ} \mathrm{~mol}^{-1} \\
\Delta S^{\neq} & =-111.87 \mathrm{~J} \mathrm{~K}^{-1} \mathrm{~mol}^{-1}
\end{aligned}
$$




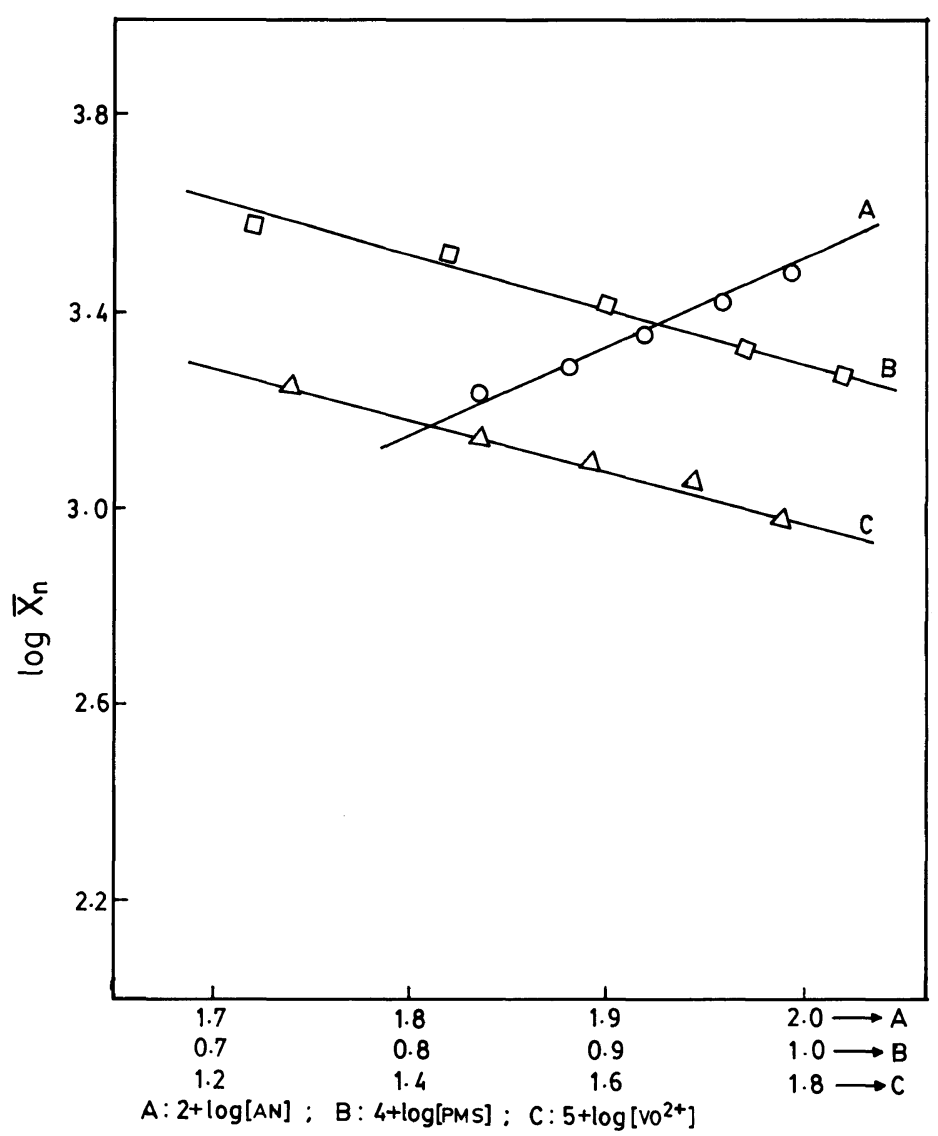

Figure 6. Effect of [monomer], $[\mathrm{PMS}]$ and $\left[\mathrm{VO}^{2+}\right]$ on degree of polymerization, $\bar{X}_{n}$.

Comparison with Peroxodiphosphate, $\mathrm{P}_{2} \mathrm{O}_{8}{ }^{4-}$

The kinetics of polymerization of acrylonitrile initiated by peroxodiphosphate $\left(\mathrm{P}_{2} \mathrm{O}_{8}{ }^{4-}\right)^{-}$ vanadyl ion in aqueous medium have been reported ${ }^{26}$ and the primary radical producing steps proposed in the reaction scheme consist of the formation of a complex between $\mathrm{VO}^{2+}$ and $\mathrm{P}_{2} \mathrm{O}_{8}{ }^{4-}$ followed by the decomposition of the complex to produce $\mathrm{HPO}_{4}{ }^{-}$as the initiating species. The formation of hydroxyl radical was also suggested and two types of termination depending upon the concentration of vanadyl ion are proposed. Mutual termination was found to occur at low concentrations of $\mathrm{VO}^{2+}\left(2.5-5.0 \times 10^{3} \mathrm{~mol} \mathrm{dm}^{-3}\right)$, whereas linear termination to be predominant in the concentration range $1.0-2.5 \times 10^{-2} \mathrm{moldm}^{-3}$.
$R_{\mathrm{p}}$ depended on [monomer] $]^{1.0},\left[\mathrm{P}_{2} \mathrm{O}_{8}{ }^{4-}\right]^{0.5}$ and $\left[\mathrm{VO}^{2+}\right]^{0.5}$ at lower concentrations of $\mathrm{VO}^{2+}$ and [monomer] ${ }^{1.0}$ and $\left[\mathrm{P}_{2} \mathrm{O}_{8}{ }^{4-}\right]^{1.0}$ and $\left[\mathrm{VO}^{2+}\right]^{0}$ at higher concentrations. The energy of activation was $28.5 \mathrm{~kJ} \mathrm{~mol}^{-1}$, which was almost one half the value estimated in this system. The $E_{\mathrm{a}}$ was higher in $\mathrm{HSO}_{5}{ }^{-}-\mathrm{VO}^{2+}$ redox system, which might be due to involvement of the monomer in coupling with complex to produce primary radicals.

\section{REFERENCES}

1. G. Manivannan and P. Maruthamuthu, Makromol. Chem., Rapid Commun., 6, 613 (1985).

2. G. Manivannan and P. Maruthamuthu, J. Polym. Sci., Chem. Ed., 24, 3393 (1986).

3. G. Manivannan and P. Maruthamuthu, Eur. Polym. 
J., 23, 311 (1987).

4. R. C. Thompson, Inorg. Chem., 20, 3745 (1981).

5. W. Roebke, M. Renz, and A. Henglein, Int. J. Radiat. Phys. Chem., 1, 39 (1969).

6. E. Hayon, A. Treinen, and J. Wilf, J. Am. Chem. Soc., 94, 47 (1972).

7. P. Maruthamuthu and P. Neta, J. Phys. Chem., 81, 937 (1977).

8. S. Saccubai, Ph. D. thesis, Madras University, Madras, January (1968).

9. F. S. Dainton and P. H. Seanıan, J. Polym. Sci., 39, 279 (1959).

10. E. Collinson, F. S. Dainton, D. R. Smith, G. J. Trudel, and S. Tazuke (in part), Discus. Faraday Soc., 29, 188 (1960).

11. M. Watanabe and H. Kiuchi, J. Polym. Sci., 58, 103 (1962).

12. E. A. S. Cavell and A. C. Meeks, Polymer, 8, 79 (1967).

13. S. Viswanathan and M. Santappa, J. Polym. Sci., Lett. Ed., 6, 629 (1968).

14. (a) I. Murai, Chem. Abstr., 44, 1849 (1950).

(b) R. J. H. Clark, "The Chemistry of Titanium and Vanadium," Elsevier Publishing Co., New York, N. Y., 1968, p 201.

15. M. L. Huggins, J. Am. Chem. Soc., 64, 2716 (1942).

16. E. O. Kraemer, Ind. Eng. Chem., 30, 1200 (1938).

17. T. Shibukawa, M. Sone, A. Uahida, and K. Iwahori, J. Polym. Sci., A-1, 6, 147 (1968).
18. K. J. Laidler, "Chemical Kinetics," 2nd Ed., Tata McGraw Hill Publishing Co., New Delhi, India, 1983, p 230.

19. J. Selbin, Chem. Rev., 65, 153 (1965).

20. C. J. Ballhausen and H. B. Gray, Inorg. Chem., 2, 426 (1963).

21. (a) V. A. Mirkin and M. J. Kozlovskii, Dokl. Akad. Nauk SSSR, 150, 317 (1963).

(b) V. A. Mirkin and M. J. Kozlovskii, Zh. Analit. Khim., 17, 704 (1962).

(c) V. A. Mirkin and M. J. Kozlovskii, Neorgan. Khim., 8, 1538 (1963).

22. V. S. Syrokomskii and L. I. Antropov, Chem. Abstr., 8, 1349 (1941).

23. (a) W. M. Latimer, "Oxidation Potentials," 2nd Ed., Prentice-Hall Inc., New York, N. Y., 1952.

(b) J. E. Carpenter, J. Am. Chem. Soc., 56, 1857 (1934).

(c) J. B. Conn, U. S. Patent, 3076, 830 (Feb. 5, 1963).

24. J. S. Littler and W. A. Waters, J. Chem. Soc., 1299 (1959).

25. M. Anderson, J. O. Edwards, Sr. A. A. Green, and Sr. M. D. Wiswell, Inorg. Chim. Acta, 3/4, 655 (1969).

26. (a) S. S. Hariharan and A. Meenakshi, Current Sci., 46, 708 (1977).

(b) S. S. Hariharan and M. Maruthamuthu, Makromol. Chem., 180, 2175 (1979). 